\title{
Room-Temperature Chemistry of Acetylene on Pd(111): Formation of Vinylidene
}

\author{
R. M. Ormerod \\ Department of Chemistry, University of Keele, Staffordshire, ST5 5BG, U.K.
}

\author{
R. M. Lambert \\ Department of Chemistry, University of Cambridge, Cambridge CB2 IEW, U.K.
}

\author{
H. Hoffmann and F. Zaera \\ Department of Chemistry, University of California, Riverside, California 92521
}

\author{
L. P. Wang, D. W. Bennett, and W. T. Tysoe* \\ Department of Chemistry and Laboratory for Surface Studies, University of Wisconsin, \\ Milwaukee, Wisconsin 53211
}

Received: August 18, 1993; In Final Form: November 23, $1993^{\circ}$

\begin{abstract}
The surface species formed following acetylene adsorption on $\operatorname{Pd}(111)$ at $300 \mathrm{~K}$ is identified as a vinylidene. It is oriented with its carbon-carbon axis tilted at $\sim 50^{\circ}$ to the surface normal which allows overlap between molecular $\pi$ orbitals and the surface d-orbitals. The carbon-carbon bond is slightly longer (by $\sim 0.03 \AA$ ) than for adsorbed ethylene on $\mathrm{Pd}(111)$. This assignment is consistent with previous photoelectron and high-resolution electron energy loss spectroscopy data. Adsorbed vinylidene decomposes to yield hydrogen and deposit carbon onto the surface at $\sim 480 \mathrm{~K}$ with an activation energy of $\sim 115 \mathrm{~kJ} / \mathrm{mol}$.
\end{abstract}

\section{Introduction}

The palladium-catalyzed formation of benzene from acetylene offers a unique opportunity for understanding the pathway of a relatively complex hydrocarbon synthesis reaction in some detail since it proceeds both at high pressure $(\sim 1 \mathrm{~atm})$ and in an ultrahigh vacuum (at $\sim 10^{-10}$ Torr).$^{1-5}$ In the latter case, approximately $30 \%$ of a saturated acetylene layer adsorbed on $\operatorname{Pd}(111)$ at $\sim 200 \mathrm{~K}$ converts to benzene. ${ }^{5}$ The general features of the reaction pathway are now reasonably well understood. . $^{6-14}$ Benzene synthesis proceeds via acetylene dimerization to form a $\mathrm{C}_{4} \mathrm{H}_{4}$ intermediate ${ }^{8}$ which consists of a tilted metallocycle, ${ }^{10,12}$ and recent calculations have shown that this exists as a stable intermediate. ${ }^{15}$ This can further react with adsorbed acetylene to form benzene. However, since initially there is insufficient space to allow the reactively formed benzene to adsorb with its molecular plane parallel to the surface, it adopts a tilted configuration, ${ }^{11-13}$ which gives riese to desorption at low temperature $(280 \mathrm{~K}){ }^{7.8}$ As the desorption sweep proceeds, the surface coverage decreases and the remaining benzene lies flat, subsequently desorbing at $\sim 520 \mathrm{~K} .7,8$ The low-temperature desorption state also results from large benzene exposures to $\mathrm{Pd}(111)$ and from co-adsorption of benzene and NO; ${ }^{13}$ in both cases, the tilted benzene layer is thought to result from a compression of the adsorbate.

Paradoxically, however, in spite of apparently facile benzene formation in an ultrahigh vacuum, the steady-state rate of benzene synthesis when catalyzed by a single-crystal sample is anomolously low $\left(\sim 10^{-2}\right.$ reactions/site/s $){ }^{4}$ Studies using high-surface-area, supported palladium show an initial extremely high benzene formation rate which diminishes to a low steady-state rate after a short time of stream, indicating that the catalyst is being poisoned..$^{5}$ Interestingly, a substantial portion of the initial rate can be recovered by the addition of a small amount of hydrogen to the reaction mixture. This is, of course, accompanied by ethylene formation in accord with the well-known activity of palladium as a hydrogenation catalyst. ${ }^{6}$

* To whom correspondence should be addressed.

- Abstract published in Advance ACS Abstracts, January 1, 1994.
Recent TPD studies on the reaction of co-adsorbed hydrogen and acetylene on $\mathrm{Pd}(111)$ show that ethylene is formed, ${ }^{17}$ and it has also been demonstrated that a flat-lying acetylenic species (identified using UPS and NEXAFS6) is the precursor to ethylene formation. ${ }^{17}$

Adsorption of acetylene on $\operatorname{Pd}(111)$ at $\sim 200 \mathrm{~K}$ results in a saturation coverage of $\sim 0.46^{7}$ (coverages are referenced to the palladium site density on the (111) face). This agrees well with the presence of a close-packed acetylenic layer on the surface. However, adsorption of acetylene at $\sim 300 \mathrm{~K}$ results in a saturation coverage of unity, ${ }^{7}$ indicating that another surface species is formed at this temperature. Simple steric arguments, therefore, suggest that this species does not adsorb with its $\mathrm{C}-\mathrm{C}$ axis parallel to the surface. In addition, co-adsorption of hydrogen and the room-temperature species on $\operatorname{Pd}(111)$ in an ultrahigh vacuum yields no ethylene or ethane desorption in temperature-programmed desorption. ${ }^{17}$ Furthermore, this species is thermally stable up to $\sim 480 \mathrm{~K}$ following which it decomposes, evolving hydrogen, and leaves carbon on the surface. It seems likely, therefore, that formation of this species from acetylene during catalysis is responsible for the diminution in rate during reaction at high temperature.

Previous ultraviolet photoelectron spectroscopic studies of the saturated layer formed by adsorption of acetylene at $300 \mathrm{~K}$ or that produced by adsorbing acetylene at $\sim 155 \mathrm{~K}$ and annealing to room temperature suggested the formation of a vinylidene species; ${ }^{7}$ this result is also consistent with HREELS data for the room-temperature, acetylene-derived overlayer. ${ }^{18}$ We have previously studied the structure of acetylene, ethylene, and $\mathrm{C}_{4} \mathrm{H}_{4}$ on palladium at low temperature using NEXAFS and ultraviolet spectroscopy:6,14,19 here we report on the nature of the acetylenic species formed at room temperature.

\section{Experimental Section}

Two sets of equipment were used, both of which have been described in detail elsewhere. ${ }^{12,20}$ Both operated at a base pressure of $\sim 1 \times 10^{-10}$ Torr, the first being equipped with a line-of-site quadrupole mass spectrometer used to obtain multiplexed tem- 


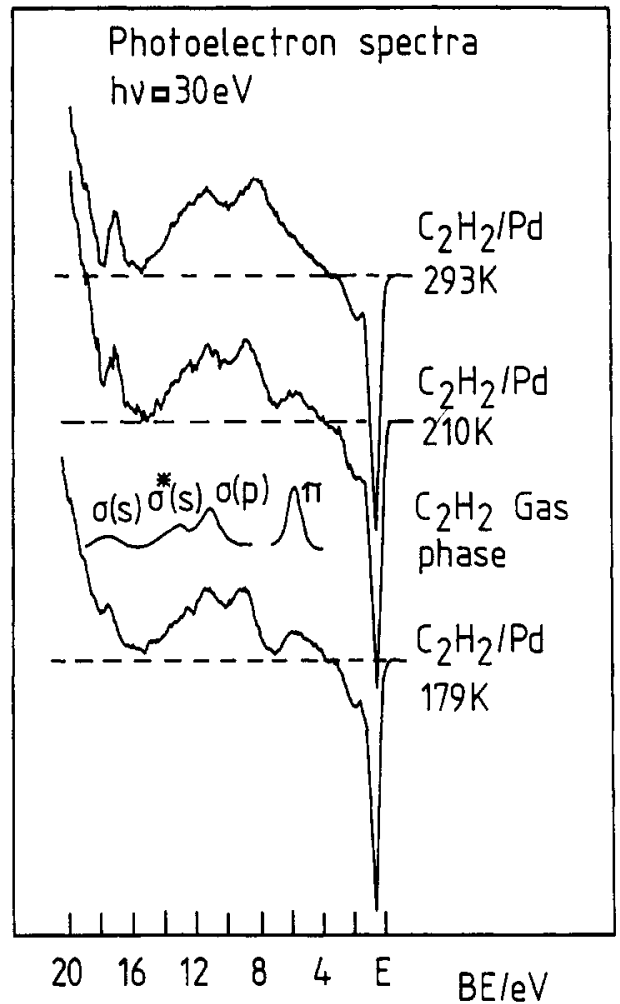

Figure 1. Angle-integrated photoelectron spectra for acetylene adsorbed on $\mathrm{Pd}(111)$ at $179 \mathrm{~K}$ and annealed to 210 and $293 \mathrm{~K}$. The annealing temperatures are marked adjacent to the corresponding spectrum, and the spectrum of gas-phase acetylene is shown for comparison. The data are displayed as difference spectra and were obtained using a photon energy of $30 \mathrm{eV}$.

perature-programmed desorption spectra. Ultraviolet and X-ray photoelectron spectra and NEXAFS data were obtained in the second chamber. Synchrotron experiments were performed at the National Synchrotron Light Source at the Brookhaven National Laboratories, as described previously. ${ }^{12}$

The $\mathrm{Pd}(111)$ single crystal was prepared using standard procedures and mounted to a rotatable sample manipulator using tantalum wires; it could be cooled to $90 \mathrm{~K}$ and heated to $\sim 1300$ K. The sample was cleaned using a standard protocol described previously, ${ }^{12,20}$ and the acetylene was purified by repeated bulbto-bulb distillations and stored in glass until use.

\section{Results}

Figure 1 shows a series of ultraviolet photoelectron difference spectra following a $2-1\left(11=1 \times 10^{-6}\right.$ Torr-s) acetylene exposure at $179 \mathrm{~K}$ (leading to a saturation coverage of 0.46 ); spectra were collected as a function of annealing temperature up to room temperature. Each spectrum was taken at the same experimental geometry after annealing to the indicated temperature for a period of $5 \mathrm{~s}$. The sample was then allowed to cool to $90 \mathrm{~K}$, at which point the spectrum was recorded using $30-\mathrm{eV}$ photons to enhance adsorbate-induced features while simultaneously minimizing the background. These difference spectra were obtained by subtracting the spectrum of clean palladium from the data for the adsorbate-covered surface. Shown also is the spectrum of gasphase acetylene.

The $179 \mathrm{~K}$ spectrum has previously been assigned to the presence of a flat-lying but distorted ( $\sim \mathrm{sp}^{2}$ rehybridized) acetylenic species; 6 it persists up to an annealing temperature of $210 \mathrm{~K}$, although some slight differences in the shape appear. The spectral profile changes significantly upon heating to $293 \mathrm{~K}$, indicating the conversion of flat-lying acetylene into another species in accord with previous ultraviolet photoelectron spectroscopy results.?

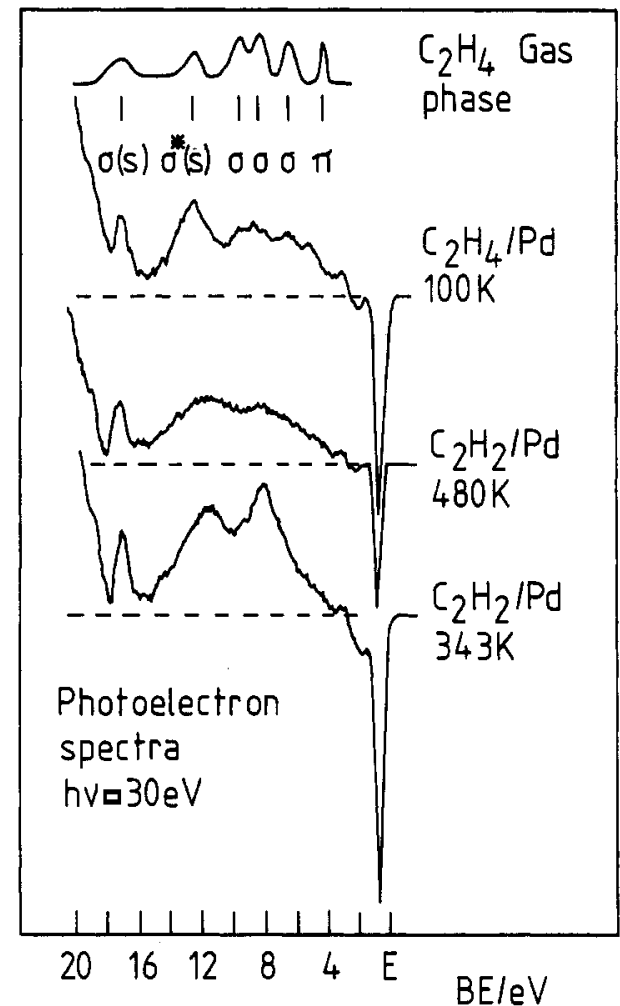

Figure 2. Angle-integrated photoelectron spectra for acetylene adsorbed on $\mathrm{Pd}(111)$ at $179 \mathrm{~K}$ and annealed to 343 and $480 \mathrm{~K}$. The annealing temperatures are marked adjacent to the corresponding spectrum, and spectra of gas-phase ethylene and ethylene adsorbed on $\mathrm{Pd}(111)$ at 100 $\mathrm{K}$ are shown for comparison. The data are displayed as difference spectra and were obtained using a photon energy of $30 \mathrm{eV}$.

The $C 1 \mathrm{~s}$ binding energy of this species is at $283.1 \pm 0.2 \mathrm{eV}$. The $C 1 \mathrm{~s}$ binding energy of adsorbed ethylene (which forms an undistorted ethylenic species) is at $283.6 \pm 0.2 \mathrm{eV}:{ }^{19}$ this shifts to $283.1 \pm 0.2 \mathrm{eV}$ on warming to $300 \mathrm{~K}$. This latter value is identical to that obtained for the room-temperature acetylenic species, suggesting that either the same species is formed in both cases or that the $C$ is binding energies are coincidentally equal. Note that ethylene adsorption on $\mathrm{Pd}(111)$ leads to the formation of ethylidyne at $300 \mathrm{~K} .21,22$ It is interesting to note also that the C $1 \mathrm{~s}$ binding energy for the $\mathrm{C}_{4} \mathrm{H}_{4}$ species formed by dichlorocyclobutene decomposition on $\mathrm{Pd}(111)$ at $\sim 200 \mathrm{~K}$ is at $284.8 \pm$ $0.2 \mathrm{eV}$, shifting to $283.2 \pm 0.2 \mathrm{eV}$ on heating to $359 \mathrm{~K}$, ${ }^{14}$ indicating that the $\mathrm{C}_{4} \mathrm{H}_{4}$ metallocycle decomposes to another surface species at this temperature, possibly that formed by either acetylene or ethylene.

Figure 2 shows the ultraviolet photoelectron spectra obtained by annealing the sample to above room temperature: the surface species at $293 \mathrm{~K}$ persists up to $343 \mathrm{~K}$, but a significant attenuation in intensity is noted on annealing to $480 \mathrm{~K}$, indicating thermal decomposition at this temperature. The spectrum of ethylene adsorbed on $\mathrm{Pd}(111)$ at $100 \mathrm{~K}$ is shown for comparison along with the spectrum of gas-phase ethylene.

Figure 3 shows a series of NEXAFS spectra collected as a function of photon incidence angle $(\theta)$ obtained at the carbon edge for a room-temperature acetylene overlayer formed by saturating a Pd(111) single crystal with acetylene at $300 \mathrm{~K}$. Note that it has been demonstrated previously ${ }^{7}$ that identical surface species are formed either by annealing the low-temperature acetylene species to $300 \mathrm{~K}$ or by direct adsorption at this temperature. Shown also is the corresponding NEXAFS spectrum for ethylene adsorbed onto $\mathrm{Pd}(111)$ at $100 \mathrm{~K}$. Both spectra were adjusted so that the Fermi edges, measured from their $C$ $1 \mathrm{~s}$ binding energies, are aligned, giving a common energy scale for electron kinetic energy relative to the Fermi level. Both the ethylene- and acetylene-derived species show sharp resonances 


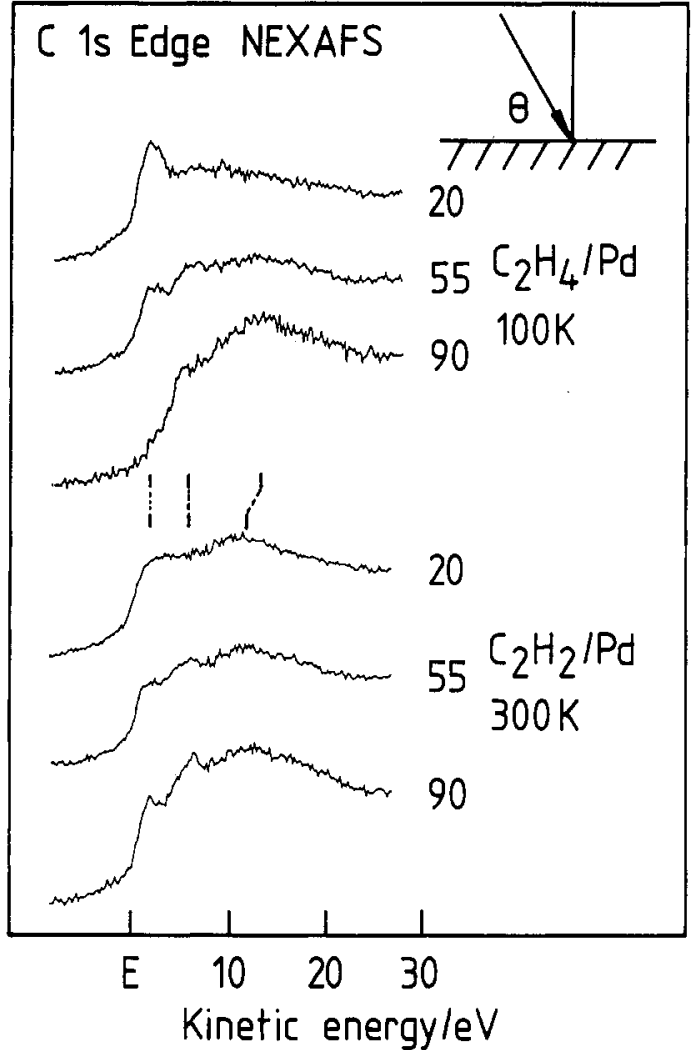

Figure 3. $\mathrm{C}$ 1s near-edge $\mathrm{X}$-ray absorption fine structure (NEXAFS) spectra for $\mathrm{C}_{2} \mathrm{H}_{4} / \mathrm{Pd}(111)$ at $100 \mathrm{~K}$ and for $\mathrm{C}_{2} \mathrm{H}_{2} / \mathrm{Pd}(111)$ at $300 \mathrm{~K}$ as a function of photon incidence angle. Incidence angles $\theta$ are measured with respect to the surface plane and are marked adjacent to their corresponding spectra.

at $2.0 \pm 0.2$ and at $5.9 \pm 0.2 \mathrm{eV}$. Note, however, that the angular variation in intensity of corresponding peaks is quite different, indicating that they adopt different geometries on the surface. In addition, a broad asymmetric resonance is observed centered at $\sim 11.8 \mathrm{eV}$ for the acetylene-derived overlayer, and at a slightly higher value of $\sim 12.8 \mathrm{eV}$ for adsorbed ethylene. This yields a difference in the position of the $\sigma$ resonances of the two spectra of $1.0 \pm 0.5 \mathrm{eV}$.

Figure 4 shows a series of temperature-programmed desorption (TPD) spectra for hydrogen ( $2 \mathrm{amu}$ ), taken at a heating rate of $30 \mathrm{~K} / \mathrm{s}$, following various acetylene exposures to $\mathrm{Pd}(111)$ at 300 $\mathrm{K}$. The initial molecular coverages are indicated. The main feature in each case is a sharp peak centered at $\sim 480 \mathrm{~K}$ which has an asymmetric profile characteristic of first-order desorption kinetics. Note that a similar, sharp 2-amu feature is evident in the TPD spectrum obtained following adsorption at $\sim 155 \mathrm{~K}$. The peak temperature in Figure 4 is also essentially constant as a function of hydrogen desorption yield, consistent with firstorder kinetics. A broad peak centered at $\sim 700 \mathrm{~K}$ is evident at higher coverages.

\section{Discussion}

The ultraviolet photoelectron spectroscopic data of Figure 1 show conversion of the initially formed $179 \mathrm{~K}$ species into another surface species on annealing to $\sim 293 \mathrm{~K}$. The $179 \mathrm{~K}$ species has previously been assigned to a distorted acetylenic molecule on the surface. ${ }^{6}$ The species formed by annealing an acetylenecovered surface to $\sim 300 \mathrm{~K}$ is also formed by acetylene adsorption at room temperature, ${ }^{7}$ yielding, in this case, a saturation coverage of 1.0 which rules out the possibility of adsorption geometries with the molecule lying parallel to the surface. It persists up to an annealing temperature of $\sim 343 \mathrm{~K}$ (Figure 2 ), but the adsorbate photoemission intensity decreases on annealing the surface to $480 \mathrm{~K}$, and the spectrum becomes significantly less well defined.

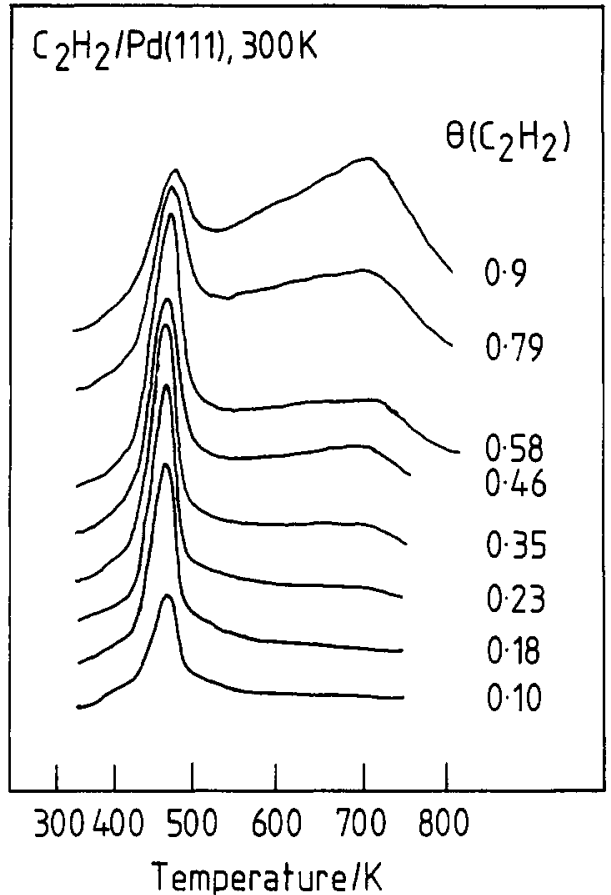

Figure 4. Hydrogen ( $2 \mathrm{amu}$ ) thermal desorption spectra obtained as a function of acetylene coverage following adsorption at $300 \mathrm{~K}$ on $\mathrm{Pd}(111)$ using a heating rate of $30 \mathrm{~K} / \mathrm{s}$. Coverages are marked adjacent to the corresponding spectrum.

As indicated by the thermal desorption data of Figure 4, this latter temperature coincides with the thermal evolution of hydrogen from the acetylene-covered surface. Chemisorbed hydrogen desorbs from $\mathrm{Pd}(111)$ in a state centered at $380 \mathrm{~K} .{ }^{23}$ These results imply that hydrogen evolution at $480 \mathrm{~K}$ in the thermal desorption spectrum shown in Figure 4 is reaction rate rather than desorption rate limited and that the shape of this peak, at least at low coverages (see below), reflects the decomposition kinetics of the species formed at room temperature. This implies that the surface species decomposes via first-order kinetics and a conventional Redhead analysis, ${ }^{24}$ using a rate constant preexponential factor of $1 \times 10^{13} \mathrm{~s}^{-1}$, yields a decomposition activation energy of $115 \pm 10 \mathrm{~kJ} / \mathrm{mol}$.

The NEXAFS spectrum of the room-temperature, acetylenederived species and that due to adsorbed ethylene (Figure 3 ) are essentially identical. It has been demonstrated previously that ethylene is $\pi$-bonded on $\mathrm{Pd}(111)$ and adsorbs with its molecular plane parallel to the surface. ${ }^{19}$ The broad peak at $\sim 12.8 \mathrm{eV}$ is assigned to a $\sigma$ resonance, and the sharp peak at $2.0 \pm 0.2 \mathrm{eV}$ is due to a $\mathrm{C} 1 \mathrm{~s}$ to $\pi^{*}$ transition. The peak at $5.9 \pm 0.2 \mathrm{eV}$ is due to a $\mathrm{CH}$ resonance. It has been shown previously25 that measurement of the Fermi edge to $\sigma$ resonance spacing for adsorbed ethylene suggested that the carbon-carbon bond is elongated (to $1.43 \AA$ ) compared with that for gas-phase ethylene (where the bond length is $1.34 \AA$ ). The corresponding peaks due to acetylene adsorption at $300 \mathrm{~K}$ are in essentially identical positions, except that the $\sigma$ resonance appears at a slightly lower kinetic energy. The position of this resonance is extremely sensitive to $\mathrm{C}-\mathrm{C}$ bond length, ${ }^{26}$ and this will be addressed in greater detail below.

The substantial difference between the photoelectron spectrum of adsorbed ethylene and that of the room-temperature, acetylenederived species (Figure 2) indicates that the latter species cannot adsorb ethylene. Additionally, adsorbed ethylene desorbs from $\operatorname{Pd}(111)$ at $\sim 300 \mathrm{~K},{ }^{19,27}$ whereas the acetylenic species persists on the surface up to $\geq 343 \mathrm{~K}$, after which it decomposes to yield hydrogen (Figure 4). The 2-amu $\left(\mathrm{H}_{2}\right)$ thermal desorption spectrum of acetylene adsorbed onto $\mathrm{Pd}(111)$ at $\sim 155 \mathrm{~K}$ also displays a prominent peak at $\sim 480 \mathrm{~K}$ (assigned to the decom- 


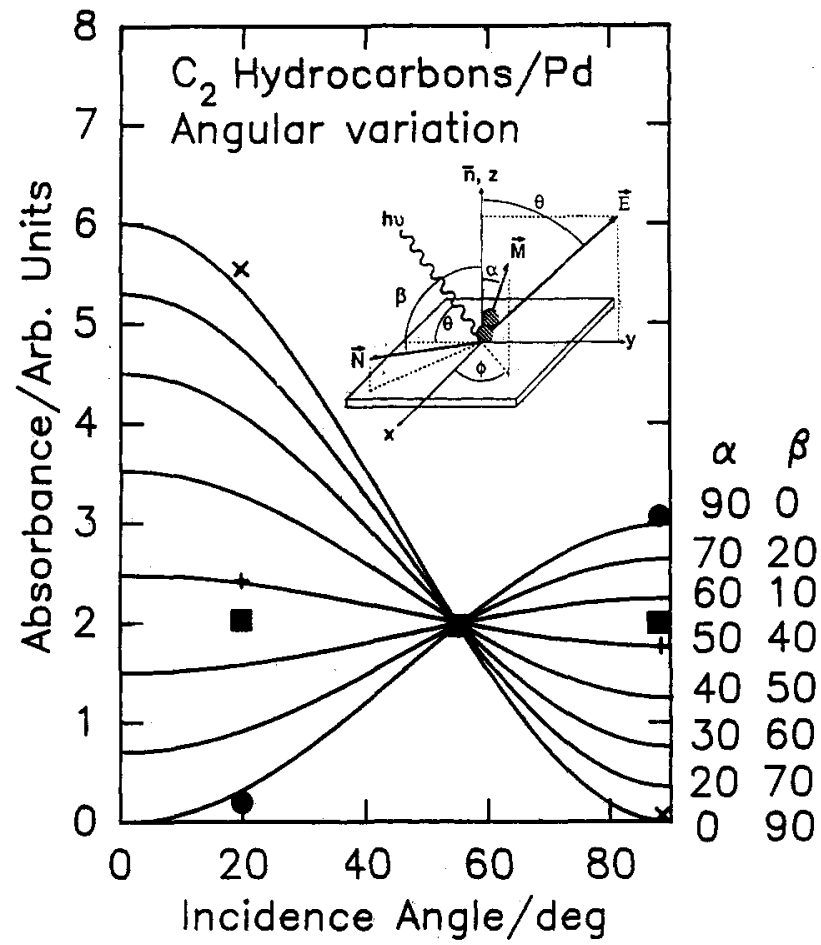

Figure 5. Angular variations of the $\pi(X)$ and $\sigma(\bullet)$ resonances for $\mathrm{C}_{2} \mathrm{H}_{4} / \mathrm{Pd}(111)$ at $100 \mathrm{~K}$ and for $\mathrm{C}_{2} \mathrm{H}_{2} / \mathrm{Pd}(111)$ at $300 \mathrm{~K}$ (+ and $\mathrm{a}$ ). The theoretical variations in these values are shown as solid lines as a function of $\alpha$ and $\beta$ which are also marked on the figure.

position of the species formed at room temperature $)^{7}$ identical to that shown in Figure 4 but little hydrogen evolution below that temperature. Taking into account that chemisorbed hydrogen desorbs from Pd(111) in a state centered at $\sim 300 \mathrm{~K}$, this implies that the stoichiometry of the room-temperature species is still $\mathrm{C}_{2} \mathrm{H}_{2}$ (identical to the initial acetylene) but with a conformation that resembles ethylene. These results taken together suggest that a surface vinylidene is formed either by annealing acetylene adsorbed at $\sim 200 \mathrm{~K}$ to room temperature or by exposing a palladium (111) surface to acetylene at $\sim 300 \mathrm{~K}$.

The angular variation in intensity of the $\pi$ and $\sigma$ resonances can be used to estimate the molecular geometry. ${ }^{28}$ It is immediately clear from the data of Figure 3 that the carboncarbon axis of vinylidene is neither parallel nor perpendicular to the surface. Figure 5 displays a set of theoretical curves for the variation in photoemission intensity as a function of $\alpha$, the angle between the molecular axis and the surface normal, and $\beta$, the angle between the direction of the $\pi$ resonances and the surface normal, as a function of photon incidence angle $\theta$ (measured with respect to the plane of the metal surface). These angles are illustrated in the inset of Figure 5. The values of $\alpha$ and $\beta$ are marked adjacent to each of the corresponding curves. Also marked on these theoretical curves are values for the angular variations in intensity of the $\pi(X)$ and $\sigma(\bullet)$ resonances for ethylene adsorbed onto $\mathrm{Pd}(111)$ at $100 \mathrm{~K}$ normalized to the intensity at $55^{\circ}$ (which is arbitrarily taken to be 2). Peak intensities are estimated from their heights and scaled to the height of the edge jump for each angle. ${ }^{12}$ This yields a value of $\alpha=90 \pm 5^{\circ}$ and $\beta=0 \pm 5^{\circ}$, indicating, in agreement with previous results, ${ }^{19,27}$ that the ethylenic carbon-carbon axis is oriented parallel to the surface. Since $\beta=0 \pm 5^{\circ}$, the plane of the ethylene molecule is also oriented parallel to the (111) face.

The angular variation in intensity of the $\pi(+)$ and $\sigma(\mathbb{E})$ resonances measured in a similar manner is also plotted in Figure 5 for vinylidene adsorbed on $\mathrm{Pd}(111)$. The $\mathrm{C}=\mathrm{C}$ axis is therefore tilted at $\sim 50^{\circ}$ to the surface normal. Note, however, that the $\mathrm{C}=\mathrm{C}$ axis can tilt in a direction either perpendicular or parallel to the $\mathrm{H}_{2} \mathrm{C}=\mathrm{C}$ plane of the molecule. A tilt of the molecular

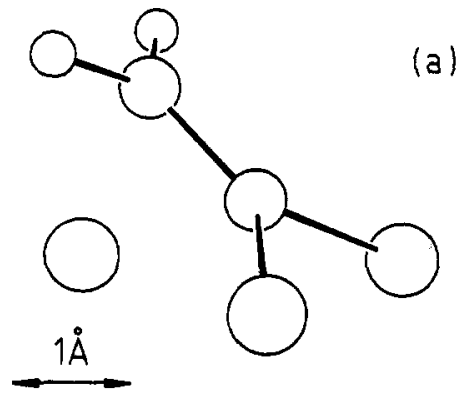

(b)

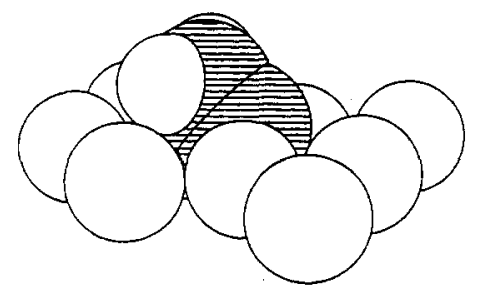

Figure 6. Proposed structure of vinylidene adsorbed on a Pd(111) surface in a (a) ball-and-stick depiction showing (b) the Van der Waals radii of the vinylidene. The scale refers to part a.

plane in a direction perpendicular to the plane of the vinylidene species would give $\alpha+\beta=90^{\circ}$. On the other hand, a tilt of the vinylidene in a plane parallel to the molecular plane would give $\beta=90^{\circ}$. Experimentally, the sum of the angles $\alpha+\beta=115 \pm$ $10^{\circ}$, slightly larger than would be expected in the former case. Note, however, that there may be slight systematic errors present since the Synchrotron radiation is not perfectly linearly polarized. Nevertheless, $\beta$ is clearly much less than $90^{\circ}$, so that the best description of the adsorption geometry corresponds to a vinylidene species with the molecular plane tilted at $\sim 50^{\circ}$ to the surface normal; this geometry is depicted in Figure 6.

It has been proposed that the Fermi edge to $\sigma$ resonance spacing can be used to measure the absolute carbon-carbon bond length for hydrocarbon species adsorbed on transition metal surfaces. ${ }^{26}$ This protocol yields a $\mathrm{C}=\mathrm{C}$ bond length for ethylene on $\mathrm{Pd}(111)$ at $100 \mathrm{~K}$ of $\sim 1.43 \AA .25$ A corresponding analysis for vinylidene indicates a $\mathrm{C}=\mathrm{C}$ bond length $\sim 0.03 \AA$ longer. Carbon-carbon single bond lengths in gas-phase hydrocarbons are $1.54 \AA$, and double bonds are $1.34 \AA$ long, ${ }^{25}$ indicating, on the basis of this analysis, a bond order in both adsorbed ethylene and vinylidene between 1 and 2. The measurement of absolute bond lengths using this method has recently been called into question. ${ }^{29}$ Nevertheless, the bond extension measured for ethylene on $\operatorname{Pd}(111)^{25}(0.09 \AA)$ is within the range measured for lowtemperature ethylene adsorption on other group VIII metal surfaces where an extension of $0.11 \AA$ is found for $\mathrm{Ni}(110),{ }^{30}$ $0.05 \AA$ for $R h(111)$, and $0.17 \AA$ for $P t(111),{ }^{31}$ while a stretch of $0.13 \AA$ was found using both EXAFS and NEXAFS for ethylene adsorbed on $\mathrm{Cu}(100)$ at $60 \mathrm{~K} .{ }^{32}$ Interestingly, however, the correspondence between the photoelectron spectum of gas-phase and adsorbed ethylene (Figure 2), where the photoemission peaks are in good agreement (except for a small shift in the $\pi$ emission due to the interaction of the $\pi$ orbitals with the surface), implies that adsorbed ethylene is not substantially distorted on $\operatorname{Pd}(111)$.

The $\mathrm{C} 1 \mathrm{~s}$ binding energies for both ethylene and acetylene on $\mathrm{Pd}(111)$ at room temperature are identical $(283.1 \pm 0.2 \mathrm{eV})$, and it is well established that ethylene evolves into ethylidyne on $\operatorname{Pd}(111)$ at room temperature..$^{21,22}$ However, the assignment of the room-temperature, acetylene-derived species to ethylidyne can be completely ruled out on the basis of both the NEXAFS and photoelectron spectra. In addition, ethylidyne is oriented so that the $\mathrm{C}-\mathrm{C}$ axis is perpendicular to the surface in complete 
contrast to the geometry measured in this case. The correspondence between the $\mathrm{C} 1 \mathrm{~s}$ binding energies in both species must therefore be coincidental. Higher resolution measurements of the $\mathrm{C} 1 \mathrm{~s} \mathrm{spectrum}{ }^{7}$ indicate the presence of two states separated by $\sim 0.8 \mathrm{eV}$, consistent with the geometry displayed in Figure 6.

Tilting of the molecular plane toward the surface leads to a stronger adsorbate-substrate bond by increasing overlap between the vinylidene $\pi$ orbitals and the substrate d-orbitals. This effect also accounts for the difference between the $C 2 p$-derived photoemission peaks for vinylidene and adsorbed ethylene (Figure $2)$. In the former case, both the $\sigma\left(\mathrm{CH}_{2}\right)$ and $\pi$ orbitals interact to a substantial extent with the substrate d-orbitals and are therefore shifted from their gas-phase positions. Additional peak shifts will also occur because of changes in $\mathrm{C}=\mathrm{C}$ bond length. In contrast, adsorbed ethylene interacts only by means of its $\pi$ orbitals, and the skeletal molecular orbitals are essentially unaffected, yielding good agreement with the gas-phase spectrum.

The 2-amu (hydrogen) thermal desorption spectrum yields an additional broad asymmetric peak centered at $\sim 700 \mathrm{~K}$ for vinylidene coverages greater than $\sim 0.5$ (Figure 4). HREELS data ${ }^{18}$ indicate the persistence of $\mathrm{C}_{x} \mathrm{H}_{y}$ fragments on palladium (111) at above $480 \mathrm{~K}$ at high acetylene coverages, and this broad hydrogen evolution state likely reflects the decomposition of these species. A similar, and even more drastic, change in decomposition kinetics as a function of coverage has been noted for benzene on Pd(111) where, in this case, thermal decomposition was found to be inhibited at higher coverages. ${ }^{13}$ Part of this effect was ascribed to the blocking of surface sites available for hydrogen at higher coverages; a similar phenomenon may affect the vinylidene decomposition kinetics in this case.

\section{Conclusions}

Adsorption of acetylene on $\mathrm{Pd}(111)$ at room temperature leads to the formation of a vinylidene species whose carbon-carbon axis is tilted so that the molecular plane is oriented at $\sim 50^{\circ}$ with respect to the surface normal. The carbon-carbon bond length of this vinylidene species is $\sim 0.03 \AA$ longer than that of ethylene molecularly adsorbed on $\mathrm{Pd}(111)$ at low temperature, which adopts a flat-lying undistorted geometry, bonding via its $\pi$ orbitals. This vinylidene species is also formed by annealing the flat-lying distorted acetylenic species, formed by adsorbing acetylene on $\operatorname{Pd}(111)$ at $\leq 200 \mathrm{~K}$, to room temperature. These results are consistent with previous photoemission and high-resolution energy loss data.

The vinylidene is stable on the $\operatorname{Pd}(111)$ surface up to $\sim 480$ $K$, when it thermally decomposes with an activation energy of $\sim 115 \mathrm{~kJ} / \mathrm{mol}$, evolving hydrogen and leaving a carbonaceous layer.
Acknowledgment. Acknowledgement is made to the donors of the Petroleum Research Fund, administered by the American Chemical Society, for partial support of this work.

\section{References and Notes}

(1) Tysoe, W. T.; Nyberg, G. L.; Lambert, R. M. J. Chem. Soc., Chem. Commun. 1983, 623.

(2) Sesselman, W.; Woratschek, B.; Ertl, G.; Küppers, J.; Haberland, Surf. Sci. 1983, 130,245

(3) Gentle, T. M.; Muetterties, E. L. J. Phys. Chem. 1983, 87, 245.

(4) Rucker, T. G.; Logan, M. A.; Gentle, T. M.; Muetterties, E. L.; Somorjai, G. A. J. Phys. Chem. 1986, 90, 2703.

(5) Ormerod, R. M.; Lambert, R. M. J. Chem. Soc., Chem. Commun. 1991,1421 .

(6) Hoffmann, H.; Zaera, F.; Ormerod, R. M.; Lambert, R. M.; Yao, J. M.: Saldin, D. K.; Wang, L. P.; Bennett, D. W.; Tysoe, W. T. Surf. Sci. $1992,268,1$. 128.

(7) Tysoe, W. T.; Nyberg, G. L.; Lambert, R. M. Surf. Sci. 1983, 135 ,

(8) Patterson, C. H.; Lambert, R. M. J. Phys. Chem. 1988, 92, 1266. 6871 .

(9) Patterson, C. H.; Lambert, R. M. J. Am. Chem. Soc. 1988, 110,

(10) Patterson, C. H.; Mundenar, J. M.; Timbrell, P. Y.; Gellman, A. J.; Lambert, R. M. Surf. Sci. 1989, 208, 93.

(11) Ormerod, R. M.; Lambert, R. M. Surf. Sci. 1990, L20, 225.

(12) Hoffmann, H.; Zaera, F.; Ormerod, R. M.; Lambert, R. M.; Wang, L. P.; Bennett, D. W.; Tysoe, W. T. Surf. Sci. 1990, 235, 259.

(13) Tysoe, W. T.; Ormerod, R. M.; Lambert, R. M.; Zgrablich, G.; Ramirez-Cuesta, A. J. Phys. Chem. 1993, 97, 3365.

(14) Ormerod, R. M.; Lambert, R. M.; Hoffmann, H.; Zaera, F.; Yao, J. M.; Saldin, D. K.; Wang, L. P.; Bennett, D. W.; Tysoe, W. T. Surf. Sci., in press.

(15) Pacchioni, G. Personal communication.

(16) German, J. E. Catalytic Conversion of Hydrocarbons; Academic Press: London, 1969; Chapter 3.

(17) Tysoe, W. T.; Ormerod, R. M.; Lambert, R. M. In preparation.

(18) Gates, J. A.; Kesmodel, L. L. Surf. Sci. 1983, 124, 68.

(19) Wang, L. P.; Tysoe, W. T.; Ormerod, R. M.; Lambert, R. M. Hoffmann, H.; Zaera, F. J. Phys. Chem. 1990, 94, 4236.

(20) Ormerod, R. M.; Lambert, R. M. J. Phys. Chem. 1992, 96, 8111.

(21) Kesmodel, L. L.; Gates, J. A. Surf. Sci. 1981, L747, 111.

(22) Lloyd, D. R.; Netzer, F. P. Surf. Sci. 1983, L249, 129.

(23) Conrad, H.; Ertl, G.; Latta, E. E. Surf. Sci. 1974, 41, 435.

(24) Redhead, P. A. Vacuum 1962, 12, 203

(25) Tables of Interatomic Distances and Configurations in Molecules nd Ions; Chemical Society, Special Publication, 1969.

(26) Stöhr, J.; Sette, F.; Johnson, A. L. Phys. Rev. Lett. 1984, 53, 1684.

(27) Tysoe, W. T.; Nyberg, G. L.; Lambert, R. M. J. Phys. Chem. 1984, $88,1960$.

(28) Stőhr, J.; Jaeger, R. Phys. Rev. 1982, B26, 4111.

(29) Piancastelli, M. N.; Lundle, D. W.; Ferrett, T. A.; Shirley, D. A. J. Chem. Phys. 1987, 86, 2765.

(30) Weinelt, M.; Huber, W.: Zebisch, P.: Steinrïck, H.-P.; Reichart, B. Birkeneuer, U.; Rösch, N. Phys. Rev. 1992, B46, 1675.

(31) Anderson, A. B.; Choe, S. J. J. Phys. Chem. 1989, 93, 6145.

(32) Arvanitis D.; Wenzel, L.; Baberschke, K. Phys. Rev. Lett. 1987, 59, 